\title{
Intestinal transit time in the population calculated from self made observations of defecation
}

\author{
C J S Probert, P M Emmett, K W Heaton
}

\begin{abstract}
Study Objectives-To assess the feasibility of estimating intestinal transit time in the general population using self recorded data on stool form, frequency of defecation, and the interdefecatory time interval.

Design-Prospective measurement of bowel function.

Setting-Bristol, Avon, UK between 1987 and 1989.

Subjects-Subjects were drawn from 1897 people who comprised $72 \cdot 2 \%$ of a stratified random sample of all men aged 40-69 years and women aged 25-69 years on the lists of 19 general medical practitioners. Altogether 1561 subjects $(59 \cdot 4 \%)$ recorded bowel function and a subsample of 98 (50 women and 48 men) had intestinal transit time measured.
\end{abstract}

Measurements and main results-The interdefecatory time interval and stool form (on a validated $1-6$ scale sensitive to transit time) were recorded prospectively from three consecutive defecations. In the subsample the mean intestinal transit time was measured simultaneously using a four marker, two stool $x$ ray technique. Multiple regression analysis was used to assess the extent to which intestinal transit time could be predicted from the defecatory data. The formulas obtained were then applied to the whole study population. In women, intestinal transit time was best predicted by the formula 103-1.23 (DF)-4.69 (SFS)+0.638 (IDTI), where DF is the stated defecation frequency per week, IDTI is the interdefecatory time interval, and SFS is the sum of the three stool form scores, for which the correlation coefficient $\mathbf{r}=\mathbf{0} \cdot \mathbf{7 3 6}$. For men the intestinal transit time $=79-1 \cdot 33$ (DF) $-1 \cdot 88$ (SFS)+0.329 (IDTI), for which the correlation coefficient $r=0 \cdot 541$. The predicted intestinal transit time was longer in women than men at equivalent ages. Women of childbearing age had longer transit times than older women.

Conclusions-Observations made by untrained subjects can be used to estimate intestinal transit time in epidemiological studies. A gender related difference in transit time exists.

f Epidemiol Community Health 1993; 47: 331-333

Slow intestinal transit has been blamed as a cause of large bowel cancer ${ }^{1}$ and, possibly, of gall stones ${ }^{2}$ and diverticular disease of the colon ${ }^{3}$ but the evidence is scanty. Slow transit is also, of course, an integral part of constipation, with its attendant discomforts and anal problems. It is desirable, therefore, to have a simple way of assessing intestinal transit time in populations so that aetiological hypotheses can be tested.

Intestinal transit time can be measured using radio-opaque markers. ${ }^{4-6}$ These techniques are time consuming, however, and expose subjects and staff to radiation or faeces. The frequency of defecation is a poor predictor of transit time. ${ }^{78}$ In 1986, Davies et $a l^{7}$ showed that intestinal transit time is well correlated with stool form or appearance. Their method, however, requires stools to be examined "in the dry" by trained observers. O'Donnell et $a l^{8}$ found that a simple, "WC based", stool form scale (the Bristol scale) yielded a reasonable correlation with transit time when used by patients with bowel symptoms, but this is not necessarily true of asymptomatic people in the community. The O'Donnell method requires subjects to keep records of six defecations ${ }^{8}$ which is probably not feasible in a population based study.

We used the Bristol scale in an epidemiological study of the prevalence and causes of gall stones, ${ }^{9}$ but recorded only three defecations per subject. Some subjects also underwent actual measurement of transit time. This gave us the opportunity to assess the extent to which intestinal transit time might be predicted from untrained observers' recordings of their stools. Since the subjects provided data on bowel frequency as well as stool form, we decided to see if these could be used to improve the prediction. This analysis led us to develop a formula which, we suggest, could be applied in future epidemiological studies.

\section{Method}

Intestinal transit time was measured using a modification of the method described by Marcus and Heaton. ${ }^{2}$ Each subject swallowed 20 radioopaque plastic markers on four consecutive mornings. The markers were of different shape but were always taken in the same order. The next two stools passed at least 24 hours after the last of the markers had been swallowed were collected and $x$ rayed. For each stool a calculation of mean transit time was made as follows:

$$
\text { Mean transit time }=\frac{s 1 \mathrm{t} 1+\mathrm{s} 2 \mathrm{t} 2+\mathrm{s} 3 \mathrm{t} 3+\mathrm{s} 4 \mathrm{t} 4}{\mathrm{~s} 1+\mathrm{s} 2+\mathrm{s} 3+\mathrm{s} 4}
$$

where $\mathrm{s} 1$ is the number of markers of the first set in the stool, $t 1$ is the time lapse (in hours) between ingestion of these markers and the passage of the stool, and so on for each set of markers. The 
calculation was performed only if there were at least two different markers in the stools. The average of the transit times from the two stools was taken as the transit time of that person at that time.

The 98 subjects in whom transit time was measured were a subsample of the 1897 volunteers who attended for ultrasonography of the gall bladder between October 1987 and March $1989 .{ }^{9}$ These 1897 people comprised $72 \cdot 2 \%$ of a stratified random sample of all the men aged 40-69 years and women aged 25-69 years on the lists of 19 general practitioners in East Bristol-an area in which virtually everyone is white and registered with a general practitioner. Younger men were not studied because gall stones are rare in this group. The subsample consisted of persons with asymptomatic and, to the subject, unknown gall stones plus gall stone free, randomly selected controls of similar age and sex. While they were undergoing measurement of their internal tranist time they made recordings of three defecations. The subjects were 50 women and 48 men $(71 \%$ of those approached).

The three stool, record form used in this study included the date and time of each stool, from which two interdefecatory time intervals were calculated. Each stool was assigned a number on the Bristol stool form scale ${ }^{8}$ as follows:

(1) Small hard lumps, like nuts;

(2) Sausage like but lumpy;

(3) Sausage or snake like with a cracked surface;

(4) Sausage or snake like, smooth and soft;

(5) Soft blobs with clear-cut edges;

(6) Fluffy pieces with ragged edges, a mushy stool.

This scale, with the addition of a seventh type (watery, no solid pieces) has been validated as reflecting not only transit time ${ }^{8}$ but also symptoms of straining and urgency. ${ }^{10}$ For each subject, a stool form score was calculated by summing the type numbers of each stool. This yielded a range from 3 (for a person who passed three type one stools (scybala)) to 18 (for a person who passed three type six stools (mushy)). The subjects' average number of defecations per week was obtained from their response to a questionnaire administered in the previous two months. ${ }^{9}$

Multiple regression analysis using Minitab software $^{11}$ was performed separately for men and women using the stool type score, the mean interval between three defecations, and the stated average number of defecations per week to predict the average transit time. The relative weights of the predictors were found by standardising each of them.

The prospective bowel record form was also available from subjects who did not undergo the

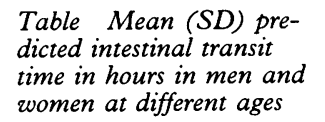

\begin{tabular}{llll}
\hline & & & $\begin{array}{l}\text { Difference } \\
\text { between men } \\
\text { and women } \\
(95 \% \mathrm{CI})\end{array}$ \\
\hline Age group (y) & Men & Women & $\begin{array}{l}66 \cdot 8(26 \cdot 2) \\
(\mathrm{n}=245)\end{array}$ \\
\hline $30-39$ & & $\begin{array}{l}62 \cdot 5(21 \cdot 3) \\
(\mathrm{n}=275)\end{array}$ & \\
$40-49$ & $\begin{array}{l}53 \cdot 2(10 \cdot 9) \\
(\mathrm{n}=329)\end{array}$ & $\begin{array}{l}62 \cdot 5(21 \cdot 7) \\
(\mathrm{n}=170)\end{array}$ & $9 \cdot 2(5 \cdot 8,12 \cdot 7)$ \\
$50-59$ & $\begin{array}{l}52 \cdot 2(11 \cdot 4) \\
(\mathrm{n}=189)\end{array}$ & $\begin{array}{l}59 \cdot 4(21 \cdot 6) \\
(\mathrm{n}=121)\end{array}$ & $6 \cdot 9(2 \cdot 9,11 \cdot 1)$ \\
$60-69$ & $\begin{array}{l}53 \cdot 0(11 \cdot 7) \\
(\mathrm{n}=159)\end{array}$ & $\begin{array}{l}59 \cdot 5(22 \cdot 1) \\
(\mathrm{n}=70)\end{array}$ & $6 \cdot 5(0 \cdot 9,12 \cdot 0)$ \\
\hline
\end{tabular}

transit time/defecation correlation studies. The whole study group was used to estimate the transit time of our population sample. This was possible in the 884 women and 677 men who provided complete records $(83.5 \%$ and $80.8 \%$ respectively of those who attended).

\section{Results}

In women intestinal transit time was best predicted by the equation:

ITT $=103-1.23(\mathrm{DF})-4.69(\mathrm{SFS})+0.638($ IDTI $)$

for which the correlation coefficient $=0 \cdot 74$. Sixty four per cent of predicted transit times were in the correct quartile and $75 \%$ of the slowest quartile of women were correctly identified. When the variables were standardised to a mean of 100 the formula became:

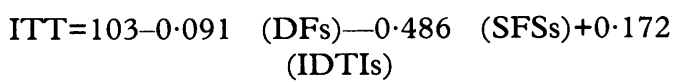

indicating that the stool form score had the greatest weighting, contributing $74 \%$ of the predicted transit time.

In men intestinal transit time was best predicted by the equation:

ITT $=79-1.33(\mathrm{DF})-1.88(\mathrm{SFS})+0.329(\mathrm{IDTI})$

for which the correlation coefficient was 0.54 . Fifty per cent of predicted transit times were in the correct tertile. Only $50 \%$ of the slowest third of men were corectly identified. When the variables were standardised the formula became:

$$
\begin{array}{ccc}
\text { ITT }=79-0 \cdot 156 \quad \begin{array}{c}
\text { (DFs) }-0 \cdot 204 \\
\text { (IDTIs) }
\end{array} & \text { (SFSs) }+0 \cdot 076
\end{array}
$$

showing that the stool form score contributed relatively less than in women, $49 \%$.

The correlation coefficient was higher for those subjects with slow predicted transit time than for those with a fast time. For example, in the slower $50 \%$ of men, for whom ITT $=118-0 \cdot 167$ (DF)0.296 (SFS) -0.003 (IDTI), the correlation coefficient was 0.645 .

The formulas were applied to the whole study population and the results for each age group are presented separately because of the varying number in each group. The results are summarised in the table. At equivalent ages, women had longer transit times than men. Age had no significant effect in men, or in women under 50 years old. Women of child bearing age (25-49 years), however, had longer transit times than older women (64.0 $v 59.4$ hours; difference 4.6 , $95 \%$ confidence interval $1 \cdot 1,8 \cdot 1$ hours).

\section{Discussion}

This study shows that observations made by untrained members of the public on just three defecations can be used to obtain an estimate of whole gut transit time which is accurate enough for epidemiological purposes, at least in women and people with a tendency to slow transit. Accuracy would doubtless be better if more than 
three defecations were studied but compliance might deteriorate.

The fact that the predictive value of this approach in men is less might be due to their having faster transit or their being less accurate observers of their stools.

Our data on predicted transit time in men and women are the first population based data on transit time apart from a study in Edinburgh. ${ }^{12}$ This failed to show a difference between men and women, but measurements were made on only 33 men and 28 women. Studies of selected volunteers, men have had faster transit than women; ${ }^{61314}$ have passed softer, bulkier stools, which implies faster transit; ${ }^{7}$ or have shown a trend in that direction. ${ }^{15} 16$ Our finding of faster transit in men is consistent with observations on bowel function in the Bristol population. ${ }^{17} \mathrm{We}$ suggest, therefore, that there is a real gender related difference in intestinal transit.

With regard to age, other studies have failed to show any effect on intestinal transit ${ }^{1318}$ but they used small numbers of subjects. We found no effect in men, albeit over a limited age range. In women, age did have an effect in that those of child bearing age had slower transit than older women. This could be an effect of female sex hormones. Our finding is consistent with a report that older women pass heavier stools than younger ones ${ }^{19}$ but direct studies of the effect of sex hormones on bowel transit need to be performed.

In conclusion, this study shows that intestinal transit time can be estimated in population surveys. To do so would add a new dimension to epidemiological studies.

Supported by grants from South West Regional Health Authority and Kellogg Company of Great Britain. C Symes and $\mathrm{H}$ Cripps helped in the collection and presentation of data.
Burkitt DP. Epidemiology of cancer of the colon and rectum. Cancer 1971; 28: 3-13.

2 Marcus SN, Heaton KW. Intestinal transit time, deoxycholic acid and the cholesterol saturation of bile-three interrelated factors. Gut 1986; 27: 550-58.

3 Painter NS, Burkitt DP. Diverticular disease of the colon: a deficiency disease of Western civilisation. BMF 1971; 2: 450-54.

4 Cummings $\mathrm{JH}$, Wiggins HS. Transit through the gut measured by analysis of a single stool. Gut 1976; 17: 219-23.

5 Cummings JH, Jenkins DJA, Wiggins HS. Measurement of the mean transit time of dietary residue through the human gut. Gut 1976; 17: 210-18.

gut. Gut 1976; 17: 210-18.
6 Metcalf AM, Phillips SF, Zinmeister AR, MacCarthy RL, Beart RW, Wolff BG. Simplified assessment of segmental colonic transit. Gastroenterology 1987; 92: 40-7.

7 Davies GJ, Crowder M, Reid B, Dickerson JWT. Bowel function measurements of individuals with different eating patterns. Gut 1986; 27: 164-9.

8 O'Donnell LJD, Virjee J, Heaton KW. Detection of pseudodiarrhoea by simple clinical assessment of intestinal transit rate. $B M \mathcal{F} 1990$; 300: $439-40$.

9 Heaton KW, Braddon FEM, Mountford RA, Hughes AO, Emmett PM. Symptomatic and silent gall stones in the community. Gut 1991; 32: 316-20.

10 Heaton KW, Ghosh S, Braddon FEM. How bad are the symptoms and bowel dysfunction of patients with irritable bowel syndrome? A prospective, controlled study with emphasis on stool form. Gut 1991; 32: 73-9.

11 Minitab reference manual. Minitab Inc, 1989. Chap 7.

12 Eastwood MA, Brydon WG, Baird JD, Elton RA, Helliwell S, Smith JH, Pritchard JL. Fecal weights and composition, serum lipids, and diet among subjects aged $18-80$ years not seeking health care. Am 7 Clin Nutr 1984; 40: 628-34.

13 Stephen AM, Wiggins HS, Englyst HN, Cole TJ, Wayman $\mathrm{BJ}$, Cummings JH. The effect of age, sex, and level of dietary $\mathrm{BJ}$, Cummings JH. The effect of age, sex, and level of dietary
fibre from wheat on large-bowel function in thirty healthy subjects. Br f Nutr 1986; 56: 349-61.

4 Rao SSC, Read NW, Brown C, Bruce C, Holdsworth CD. Studies on the mechanism of bowel disturbance in ulcerative colitis. Gastroenterology 1987; 93: 934-40.

15 Wyman JB, Heaton KW, Manning AP, Wicks ACB Variability of colonic function in healthy subjects. Gut 1978; 19: $146-50$.

16 Hinds JP, Stoney B, Wald A. Does gender or the menstrual cycle affect colonic transit? Am F Gastroenterol 1989; 84: 123-6.

17 Heaton KW, Radvan J, Cripps H, Mountford RA, Braddon FEM, Hughes AO. Defaecation frequency and timing, stool form in the general population - a prospective study. Gut 1992; 33: 818-24

18 Gear JSS, Brodribb AJM, Ware A, Mann JI. Fibre and bowel transit times. Br $\mathcal{F}$ Nutr 1991; 45: 77-82.

19 Brauer PM, Slavin JL, Marlett JA. Apparent digestibility of neutral detergent fibre in elderly and young adults. $A m \mathcal{F}$ Clin Nutr 1981; 34: 1061-70. 